\title{
Marina de Saavedra, una mujer en la frontera confesional (Zamora, 1558-1559) ${ }^{1}$
}

\author{
Doris Moreno Martínez \\ Universidad Autónoma de Barcelona \\ doris.moreno@uab.cat
}

Recibido: 9 de junio de 2014

Aceptado: 15 de diciembre de 2014

\section{RESUMEN}

En este artículo se estudia el caso de la zamorana Marina de Saavedra, acusada de protestantismo en 1558. Se reconstruye su contexto familiar y social, y su lugar en la red de relaciones creadas por los líderes del protestantismo castellano. Se aborda la naturaleza de sus creencias y su proceso, así como las actuaciones de su familia para recuperar el capital económico, social y simbólico del linaje después de la condena inquisitorial. Se pone en evidencia cómo las creencias protestantes circularon de manera fluida sobre el sustrato de la piedad castellana bajomedieval y el papel de las mujeres en esa circulación.

Palabras clave: inquisición, protestantismo castellano, mujeres, identidad confesional.

\section{Marina de Saavedra: A Devout Laywoman on a Confessional Frontier (Zamora, 1558-1559)}

\begin{abstract}
In this article is estudied the case of Zamora's Marina de Saavedra, accused of Protestantism in 1558. Her family and social context is reconstructed, and her place in the network of relationships created by the leaders of Castilian Protestantism. The nature of their beliefs and her process is discussed and the efforts of her family to recover the economic, social and symbolic capital of the lineage after the inquisitorial sentence. It demonstrates how the Protestant beliefs circulated fluidly on the substrate of the late medieval Castilian piety and the role of women in this process.
\end{abstract}

Key words: Inquisition, Castilian Protestantism, Women, Confessional Identity.

\footnotetext{
1 Este estudio se integra en el marco del Proyecto de Investigación HAR2011-26002, financiado por el Ministerio de Ciencia e Innovación del Gobierno de España.
} 


\section{LA FRONTERA CONFESIONAL}

Mucho se ha escrito sobre el llamado grupo luterano de Valladolid. En el siglo XIX, Juan Antonio Llorente, Adolfo de Castro, Benjamin W. Wiffen, Luis Usoz y Río, Marcelino Menéndez Pelayo y Ernst H. J. Schäfer contribuyeron desde posicionamientos ideológicos muy distintos a la recopilación documental esencial sobre aquellos hombres y mujeres procesados por la Inquisición española en 1558-1561. Ninguno de ellos cuestionó su identidad protestante 2 .

En el siglo XX, fue Marcel Bataillon el que puso en duda esa identificación en su extraordinario libro sobre la recepción de Erasmo en la España del siglo XVI. El protestantismo llegó a España tarde, y no encontró espacio donde arraigar porque el erasmismo, previo, ya había colmado las ansias de renovación espiritual de amplios sectores españoles. Para el hispanista francés, las prácticas de los grupos luteranos castellanos se explicaban mejor en la matriz alumbrada autóctona que en un auténtico culto reformado. En todo caso, se trataba de un "protestantismo" diluido, de baja intensidad, que no mereció vivir en las hermosas páginas de su libro sin la constricción de las comillas ${ }^{3}$.

José C. Nieto, por su parte, defendió que los grupos de Sevilla y Valladolid procesados por el Santo Oficio eran claramente protestantes en sintonía con la Reforma de allende los Alpes aunque, lejos del tradicional difusionismo norte-sur, estos grupos eran el producto genuino de una reforma de matriz española en la que Juan de Valdés habría jugado un papel esencial ${ }^{4}$. José Ignacio Tellechea, a su vez, desestimó cualquier duda al respecto. A su juicio, el núcleo dogmático fundamental y típico del protestantismo (redención y satisfacción de Cristo, fe y certeza, libre voluntad, iglesia, sacramentos, y las derivaciones lógicas de estos principios) estaba claramente presente en los testimonios de los procesados principales, con derivaciones que incluían críticas anticlericales tradicionales. Aunque eso sí, no todos los procesados en estas fechas estaban iniciados por igual en las nuevas doctrinas y formas. Es decir, un número importante de los procesados por luteranismo a mediados del siglo XVI estaba situado en una frontera indefinida, un punto entre ortodoxia y heterodoxia, y no muy fijo ${ }^{5}$.

En los últimos años, y en el marco de una renovación historiográfica de la historia religiosa, las nuevas investigaciones y lecturas que se vienen haciendo de las sensibilidades religiosas españolas del siglo XVI están contribuyendo a conocer más y

2 Para una bibliografía completa sobre el tema: LutTikHuizen, F.: La Reforma en España, Italia y Portugal, siglos XVI y XVII. Bibliografía actualizada, Sevilla, Editorial Eduforma, 2009.

3 Bataillon, M.: Erasmo y España, México, Fondo de Cultura Económica, 1966, p. 706.

4 Nieto, J. C.: Juan de Valdés and the origins of the Spanish and Italian Reformations, Genève, Droz, 1970 .

5 Tellechea Idígoras, J. I.: “El protestantismo castellano (1558-1559): un 'topos' (M. Bataillon) convertido en ‘tópico' historiográfico”, en Revuelta Sañudo, M. y Morón Arroyo, C. (eds.): El erasmismo en España, Santander, Sociedad Menéndez Pelayo, 1986, pp. 304-322; Tellechea Idígoras, J. I.: "Perfil teológico del protestantismo castellano del siglo XVI: Un Memorial inédito de la Inquisición, 1559”, Diálogo Ecuménico, 17 (1982), pp. 315-333. También afirmaron la identidad genuinamente protestante de algunos personajes acusados de luteranismo en Valladolid y Sevilla, Ronald Truman y Arthur Gordon Kinder, cuya abundante bibliografía puede ser consultada en el libro de F. LutTiKHUizen citado en la nota 2. 
mejor estos grupos. Los trabajos de Werner Thomas, con un análisis de larga duración, Michel Boeglin y Tomás López Muñoz sobre los procesados de Sevilla, con aportaciones documentales nuevas, constituyen una destacada aportación, así como la monografía de Stefania Pastore que centrada en el análisis preciso del valdesianismo y el alumbradismo español a través de vidas y personajes como Constantino de la Fuente, ha contribuido enormemente a repensar y debatir la cuestión de las identidades confesionales en la España de la primera mitad del XVI. Sin embargo, todavía hay mucho por hacer. Los procesados por luteranismo en la España de mediados del XVI reclaman nuevos estudios que atiendan de manera fina a la difusión dinámica de las nuevas ideas entre ellos, a su composición sociológica, sus prácticas religiosas, sus formas de comunicación, sus relaciones con las órdenes religiosas, el papel de las mujeres, etc ${ }^{6}$.

En este trabajo, los grupos luteranos castellanos (Valladolid, Pedrosa del Rey, Toro, Zamora, Palencia, Logroño) serán nuestro marco de referencia. Tellechea Idígoras ha sido en los últimos años, al calor de su interés por la figura del arzobispo de Toledo Bartolomé de Carranza y su proceso inquisitorial, quien más y mejor ha estudiado estos grupos. Gracias a su extraordinaria labor sabemos más del papel jugado por los Cazalla, Pedro y Agustín (siempre con la sombra de su pariente María de Cazalla detrás); el italiano D. Carlos de Seso o Juan Sánchez, el personaje que inspiró la extraordinaria novela de Miguel Delibes El Hereje; las relaciones del grupo con el valdesianismo, los textos reformados, el perfil teológico del grupo... ${ }^{7}$ Muy poco sabemos, sin embargo, de las mujeres implicadas. Monjas, beatas y espirituales, tuvieron un papel muy relevante en estos grupos. Muchas de ellas fueron lo suficientemente letradas como para leer, en castellano y en latín, y por sus manos pasaron muchos de los textos, manuscritos e impresos, que alimentaron a los diferentes grupos. Con ávida curiosidad se acercaban a los textos bíblicos y se deleitaban en conversaciones espirituales. Su reconocimiento social las situaba en una posición de autoridad espiritual no ajena a la difusión discreta de las nuevas ideas y prácticas. En Pedrosa del Rey, Pedro de Cazalla tutelaba una casa de beatas muy activas. En Valladolid, las personalidades femeninas más destacadas en la difusión de las nuevas ideas eran las beatas Juana Sánchez, que se suicidó en la cárcel, y Beatriz de Cazalla, mientras que un número importantísimo de las monjas de los conventos de Belén y Santa Catalina se vieron implicadas. En Toro, la marquesa de Alcañices D. ${ }^{a}$ Elvira de Rojas daba cobertura a su hija D. ${ }^{a}$ Ana Enríquez y su círculo de amigas y criadas. En Zamora, se mencionan hasta veinte mujeres participando de una forma $u$ otra en encuentros y conversaciones. Más de la mitad de todos los procesados de esta ciudad y sus alrededores eran mujeres. Entre todas ellas destacó Marina de Saavedra, un mujer devota.

6 Pastore, S.: Una herejía española, Madrid, Marcial Pons, 2010; Boeglin, M.: "Evangelismo y sensibilidad religiosa en la Sevilla del Quinientos: consideraciones acerca de la represión de los luteranos sevillanos", Studia Historica. Historia Moderna, 27 (2005), pp. 163-189; Almenara, M. y Ardit, M.: "Nuevas perspectivas sobre los movimientos protestantes valencianos en el siglo XVI", Estudis: Revista de historia moderna, 23 (1997), pp. 75-100; Thomas, W.: La represión del protestantismo en España, 1517-1648, Leuven, Leuven University Press, 2001.

7 Tellechea Idígoras, J. I.: "Prolegómenos jurídicos del proceso de Carranza. Los protestantes de Valladolid", Anthologica Annua, 7 (1959), pp. 215-336. Para una bibliografía completa de la importante obra de Tellechea Idígoras puede verse: http://www.fundaciontellechea.org/bibliografia.html 
El grupo protestante de Zamora se formó a partir del proselitismo de Cristóbal de Padilla, pero el eje alrededor del que giraron la mayoría de sus componentes fue Marina de Saavedra, una mujer iletrada y casada. No estamos ante una "madre espiritual" al estilo de otras procesadas por el Santo Oficio como Isabel de la Cruz, Francisca Hernández o María de Cazalla. Ni siquiera ante una beata puesto que estaba casada. Sin embargo, la influencia de Marina de Saavedra en su entorno fue sostenida y relevante, a pesar de que ella intentase minimizar su papel ante los inquisidores ${ }^{8}$. De la lectura del proceso inquisitorial se puede concluir que era plenamente consciente de que sus nuevas creencias chocaban con la ortodoxia aceptada. Los inquisidores creyeron, en función de su proceso y de los procesos de los demás implicados, que Marina de Saavedra había creído durante algunos meses en los dogmas del protestantismo.

\section{EL CONTEXTO DE MARINA DE SAAVEDRA}

Marina de Saavedra nació hacia 1509 en Zamora, hija de dos familias originarias de la montaña santanderina y la ciudad de Toro. Abuelos y tíos paternos tenían una larga hoja de servicios a la Corona así como diversas prebendas eclesiásticas. Marina de Saavedra se quedó huérfana relativamente pronto y estuvo al cuidado de su tío Gregorio Macías, canónigo de Zamora y secretario del prior de la orden de San Juan de Jerusalén, fray Diego de Toledo, que tenía la sede de la provincia o también llamada lengua de Castilla en Zamora. Fue el canónigo Macías quien firmó su carta de dote en 1534. Varios indicios indican que Marina de Saavedra creció en un ambiente de devoción y piedad afectiva. El canónigo Macías tenía una estrecha relación con los círculos espirituales castellanos de aquellas décadas. Estaba, por ejemplo, próximo a los dominicos de San Gregorio de Valladolid a través de su compañero de cabildo Sabino Astete, fidelísimo discípulo y amigo del dominico Bartolomé de Carranza. Y una nota en su testamento, otorgado en 1550, sugiere contactos con Juan de Ávila y su escuela: afirmaba que había financiado varias obras de mejora en su parroquia de Santa María de la Horta con motivo de la visita de Juan de Ávila9 .

Del análisis de la pequeña biblioteca inventariada a la muerte del canónigo zamorano en 1551, emerge la personalidad de un hombre de iglesia de varios y amplios intereses. En el ámbito de su oficio, encontramos una Doctrina cristiana (¿quizá la de Juan de Ávila?), la Exposición sobre los tres capitulos primeros del Apocalipsis del benedictino Alonso Gómez (Sevilla, 1546), un Espejo de conciencia (quizá la edición de Toledo de 1525), un Flos Sanctorum y, sobre todo, el Aviso de curas de, probablemente, el obispo de Calahorra y reformador Bernal Díaz de Luco, amigo de

\footnotetext{
8 Prosperi, A.: "Dalle 'divine madri' ai padri spirituali”, en Schulte van Kessel, S. (cur.), Donne e uomini nelle cultura spirituale, La Haya, Netherlands Government Publishing Office, 1986, pp. 71-90. ATIENZA LóPEZ, A.: "De beaterios a conventos. Nuevas perspectiva sobre el mundo de las beatas en la España Moderna", Historia Social, 57 (2007), pp. 145-168.

9 Archivo Histórico Nacional (AHN), Inquisición, leg. 4599, exp. 7, fol. 122v. Sobre la influencia de Juan de Ávila en las ciudades castellanas Bilinkoff, J.: Avila de Santa Teresa, Madrid, Editorial de Espiritualidad, 1989, pp. 88-95.
} 
Don Carlos de Seso, la Memoria de nuestra redención o Tratado de la misa firmado por Sancho Pérez Machuca (Valladolid, 1497) y posteriormente atribuida a Hernando de Talavera. Otros libros nos sugieren un interés genuino por la historia de España y universal (Pedro de Medina y su Libro de grandezas y cosas memorables de España, Sevilla, 1548 o 1549; fray Alonso Venero OP y su Enchiridion de los tiempos, una historia universal que a partir de la edición de 1549 incluyó el descubrimiento de las Indias) y la literatura de viajes, bien representada con John Mandeville y su Libro de las maravillas del mundo y del viaje de la Tierra Santa de Jerusalén, que tuvo varias ediciones. El mundo clásico estaba representado por Guido della Colonna y su Crónica troyana y La cien novelas de Juan Bocacio, el Decamerón ${ }^{10}$.

Ciertamente, es difícil precisar la influencia que el canónigo Gregorio Macías pudo ejercer sobre su sobrina. Sabemos que ella no sabía leer, pero sí parecía habituada a la lectura en común. Y por otro lado, las disposiciones testamentarias del canónigo apuntaban a una relación de confianza y proximidad. Estos indicios sugieren que, por lo menos, Marina de Saavedra creció en un entorno abierto a la circulación de noticias e ideas y en un humus de religiosidad afectiva.

Su matrimonio con Pablo Cisneros de Sotelo (o también Sotelo de Cisneros) en 1534 acentuó ese horizonte abierto. Cisneros de Sotelo, viudo con hijos, era miembro de un importante linaje hidalgo de Zamora que desde finales del siglo XV prestaba importantes servicios a su ciudad (regidores, letrados y representantes en Cortes), a la alta nobleza castellana (administradores, consejeros) y a la monarquía (soldados y conquistadores). Tres fuentes de riqueza y poder que los Sotelo, padres, tíos y hermanos de Pablo Cisneros de Sotelo supieron explotar muy bien. Parientes de fray Diego de Deza, arzobispo de Sevilla (1504-23) e Inquisidor General (1498-1507), los hermanos Alonso y Francisco de Sotelo ocuparon diversos oficios bajo su protección. El primero fue receptor del Santo Oficio en los obispados de Cuenca, Sigüenza, Calahorra, Osma, Palencia y Valladolid a principios del XVI y el segundo fue su mano derecha hasta el mismo momento de su muerte en Sevilla. En ese momento, Alonso de Sotelo, comendador de Santiago, pasó a convertirse en mayordomo del duque de Medinasidonia. Este Sotelo financió la conquista de América hasta 1504 y ordenó la fundación del zamorano Hospital de Sotelo para mujeres en 1526, haciendo a los Sotelo patronos perpetuos ${ }^{11}$.

Como conquistadores, Antonio de Sotelo acompañó a Hernán Cortés en la conquista de México, reedificando la iglesia parroquial de San Andrés de Zamora y ordenando una bella capilla para los Sotelo y una tumba con orante que fue esculpida por Pompeo Leoni. Su hermano, Gregorio de Sotelo, hizo su fortuna en el Perú como encomendero antes de volver a Zamora a principios de los años 50 del XVI. Bernardo de Sotelo acompañó a Cortés y a Almagro. Juan de Sotelo, conquistador de Panamá,

10 AHN, Inquisición, leg. 4599, exp. 7, fol. 169.

11 Cotarelo Valledor, A.: Fray Diego de Deza: ensayo biográfico, Madrid, José Martínez y Perales, 1902, p. 160. Fernández-Prieto, E.: "El Hospital de Sotelo y el régimen establecido para el mismo en el testamento del fundador en 1530", Anuario Instituto de Estudios Zamoranos “Florián de Ocampo", (1993), pp. 487-508. 
murió dejando una importante fortuna que obligó a Pablo Cisneros de Sotelo a viajar a Tierra Firme para reclamar la herencia ${ }^{12}$.

Finalmente, a partir de los años cuarenta, Pablo Cisneros tuvo una actividad cada vez más importante en el gobierno de la ciudad junto a otros hidalgos como Hernando Delgadillo, también pariente, con el que fue procurador a Cortes en 1555. Esta nobleza zamorana era un estamento social fuerte, cohesionado y de un enorme peso en la vida pública de la ciudad. Cuando Marina de Saavedra se casó con el hidalgo Cisneros de Sotelo tuvo acceso privilegiado a un nuevo mundo lleno de informaciones y noticias increíbles, de aventuras de conquista y de riquezas, pero también a un mundo local muy rico, a unas redes sociales y políticas muy cohesionadas ${ }^{13}$.

Este entorno familiar tenía un profundo anclaje en la sociedad zamorana, una sociedad en la que el peso de la iglesia y de una religiosidad comunitaria eran muy destacados. Con 7.745 habitantes, Zamora tenía a mediados del XVI treinta parroquias, a las cuales se adscribían diferentes cofradías, además de dieciséis establecimientos religiosos, once femeninos y cinco masculinos. A estos establecimientos se añadían los beaterios ${ }^{14}$.

Debido en parte a la emigración masculina a América, la población femenina de Zamora había ganado un lugar destacado en la sociología de la ciudad. Mujeres solas, viudas, solteras e incluso casadas pero sin marido presente eran una realidad. Por otro lado, la pobreza acuciaba los hogares de muchas de estas mujeres. En 1561, las viudas constituían el $24 \%$ de todas las casas zamoranas y entre los pobres, aproximadamente un $30 \%$ de los 7.745 habitantes, las mujeres solas suponían el 66,4\%. ${ }^{15}$ Para poder afrontar una supervivencia difícil las mujeres se acogían unas a otras formando redes de solidaridad doméstica que era vista con enorme recelo por las autoridades. Ello explica que en los años 40 del siglo XVI los regidores de Zamora otorgaran varias Ordenanzas de orden público sobre ello:

Vista la desolación de mozas solteras que tienen casa por sí y con otras mujeres, donde se hacen muchos insultos y alcahueterías, ninguna moza soltera que no sea casada o viuda tenga casa por sí, ni ninguna mujer casada ni viuda las tenga en su guarda o en su compañía, so pena de que sean desterradas de la ciudad por un año, veinte días de cárcel y doscientos maravedíes para la justicia ${ }^{16}$.

En este contexto es en el que surgieron varios beaterios a lo largo de la primera mitad del siglo XVI, la mayoría adscritos a la orden tercera franciscana, como los beaterios de Santa Marina, Santa Marta y San Bernabé, Santa Paula, o sin regla, como el de Santa Isabel, extramuros de la ciudad. Estos beaterios eran núcleos dinámicos

\footnotetext{
12 Archivo General de Indias (AGI), Lima, 565,L. 2, fol. 144 y 22; y Panamá, 234, L. 4, fols. 106v-107v.

13 Véase al respecto Carretero Zamora, J. M.: Cortes, monarquía, ciudades. Las Cortes de Castilla a comienzos de la época moderna (1476-1515), Madrid, S. XXI, 1988, p. 325.

14 Flynn, M. M.: Confraternal piety in Zamora in the late medieval and Early Modern period, Tesis doctoral, Madison, 1985, p. 86a.

15 Para la población de Zamora, Rueda FernándeZ, J. C.: "Zamora en los siglos XVI y XVII. Estudios demográficos", Studia Zamorensia, 2 (1981), pp. 117-134.

16 Fernández Duro, C.: Memorias históricas de la ciudad de Zamora, Madrid, 4 vols., 1882, vol. II, p. 265.
} 
de prácticas y sociabilidades vinculadas a la efervescencia religiosa castellana de un catolicismo plural ${ }^{17}$.

Sobre esta red de iglesias, monasterios y beaterios se levantaba el mundo de las cofradías. Zamora tenía a mediados del siglo XVI ciento cincuenta y tres cofradías. Valladolid tenía cerca de 100 cofradías para una población de 30.000 habitantes. Toledo con 60.000 residentes y 143 cofradías elevaba la media pero nada comparable a las cifras de Zamora. Florencia (59.000 hab.) y Lyon, con poblaciones similares a Toledo tenían 75 y 65 cofradías respectivamente. Para hacernos una idea: en Zamora había una cofradía por cada 14 casas mientras en muchas partes de Castilla la Nueva (Toro, Valladolid, Palencia...) la ratio más normal era la de una cofradía por cada 100 casas. Con un 30\% de población pobre según los censos, las cofradías zamoranas crearon una auténtica red social en la ciudad y su entorno con una organización y unos ritmos distintivos en los que participaban un porcentaje elevadísimo de zamoranos.

La mayoría de las cofradías zamoranas eran cofradías de piedad vinculadas a los diferentes estamentos (existieron cofradías de nobles, de sacerdotes, gremiales...) en las que se estimulaba la práctica de la caridad como elemento sustancial de la imitatio Christi: atender a hambrientos y sedientos, vestir al desnudo, visitar a los enfermos y acompañar a los muertos, rescatar a los cautivos y alojar a los desvalidos. La solidaridad interna entre los miembros era buscada activamente a través de comidas comunes y encuentros religiosos. Solidarias eran también las devociones: cada cofradía rendía culto a una imagen o advocación determinada. El peso social de estas cofradías era muy importante. Tenían sus propias parroquias y capellanes, eran llamadas para participar en las rogativas públicas en tiempos de necesidad y ocupaban activamente el espacio público en la celebración de sus santos patrones. Las devociones comunitarias, públicas o semipúblicas, incluían la confesión pública de pecados y la restitución después de la absolución de los sacerdotes. Los miembros de las cofradías atendían solidariamente a los moribundos e incluso desempeñaron responsabilidades que después de Trento fueron reservadas a los curas parroquiales, como llevar la extremaunción a los moribundos y anunciar las muertes al público mediante el toque de campanas ${ }^{18}$. William Christian llamó la atención sobre el fuerte sentimiento de hermandad universal de los creyentes en España estimulado por esta sociabilidad religiosa tan intensa, un sentimiento que era casi tan amenazante para el clero católico como el concepto de sacerdocio universal de los protestantes ${ }^{19}$. Desde mediados del Quinientos y especialmente después de Trento, encontramos un intervencionismo creciente de la jerarquía eclesiástica para controlar las cofradías y ponerlas bajo su supervisión y control. Las razones parecen evidentes. Las cofradías eran un espacio de sociabilidad, especialmente urbana, donde los laicos podían desarrollar formas de

17 Lorenzo Pinar, F. J.: "Monjas disidentes. Las resistencias a la clausura en Zamora tras el Concilio de Trento", en Mestre Sanchís, A. y Giménez López, E. (eds.): Disidencias y exilios en la España Moderna, Universidad de Alicante, 1997, pp. 7-80.

18 Flynn, M. M.: “Charitable Ritual in Late Medieval and Early Modern Spain”, The Sixteenth Century Journal, 16/3 (autum, 1985), pp. 335-348.

19 Christian, W.: Religiosidad local en la España de Felipe II, Madrid, Nerea, 1991, p. 307. Para Valladolid, con la misma opinión, Bennassar, B.: Valladolid en el siglo de oro. Una ciudad de Castilla y su entorno agrario en el siglo XVI, Valladolid, Ámbito, 1983, p. 390. 
espiritualidad y piedad religiosa con amplio margen de discrecionalidad, sin la tutela rigurosa de la autoridad eclesiástica. Era necesario articular y controlar mejor ese espacio bisagra donde se encontraban laicos y religiosos ${ }^{20}$.

Marina de Saavedra debe ser entendida en este contexto, el de una sociedad urbana donde las obras de caridad formaban parte de una religiosidad de dimensión comunitaria en la que se encontraban en el espacio público y en espacios reservados nobles, canónigos, monjes y monjas, curas, beatas, artesanos y gentes de todo tipo y condición. La influencia de este ambiente social y religioso de la Zamora del XVI fue muy importante. La presencia femenina en estos espacios y círculos fue muy destacada y socialmente valorada. En este humus fecundo creció el protestantismo zamorano. No es descabellado deducir la pertenencia de Marina de Saavedra a una o varias de estas cofradías a partir de la reconstrucción de su particular geografía de piedad ${ }^{21}$.

\section{GEOGRAFÍAS ÍNTIMAS DE UNA MUJER DEVOTA}

La fuente documental principal para acercarnos a Marina de Saavedra es el proceso inquisitorial que le abrió la Inquisición en la primavera de $1558^{22}$.

Los testigos nos presentan a una mujer de salud frágil -sufría periódicamente ataques de perlesía-, muy inclinada a las prácticas de piedad. Entre sus vecinos tenía fama de mujer de mucho recogimiento desde que era doncella: "e que desde que era doncella era mujer de mucho recogimiento" ${ }^{23}$. Tenía oratorio personal en su casa, símbolo de su estatus socioeconómico, en el que se recogía para la meditación y desde el que, primero en susurros y después a gritos desde 1557 pedía a Dios: "Señor yo creo lo que mandas que crea" ${ }^{24}$. Confesaba regularmente cada quince días, tanto en su parroquia de Santa María de la Horta como en otras iglesias y conventos. Asistía habitualmente a bien morir a los enfermos y suscitaba la admiración de sus vecinos por su entrega en la asistencia a enfermos y pobres en los hospitales de la ciudad. Sus penitencias y ayunos la llevaban al límite, hasta que "casi quedaba medio muerta"25. En su casa recogía y alimentaba siempre a seis pobres y quince días antes de la Pascua de flores de 1558 había recogido en su casa a varios niños expósitos ${ }^{26}$.

Desde finales de 1557 algo empezó a cambiar en su vida a través de una relación más estrecha con Cristóbal de Padilla, miembro del núcleo duro del protestantismo

20 Terpstra, N., Prosperi, A. y Pastore, S. (eds.): Faith's Boundaries: Laity and Clergy in Early Modern Confraternities, Turnout, Brepols, 2013. Para España, Arias de SaAvedra, I., y López-Guadalupe, M. L.: "Las cofradías y su dimensión social en la España del Antiguo Régimen”, Cuadernos de Historia Moderna, 25 (2000), pp. 189-232. Una breve síntesis en CALlaHAn, W.: "Confraternities and Brotherhoods in Spain, 15001800", Confraternitas, 12:1 (2001), pp. 17-25.

21 Jodi Bilinkoff puso de relieve la importancia de estos contextos urbanos castellanos en el siglo XVI para entender plenamente personalidades tan extraordinarias como Teresa de Jesús en su importante estudio citado en n. 9.

22 Bibliotheque National de France (BNF), Mss. Esp. 456.

23 Ibidem, fol. 18v.

24 Ibidem, fol. 56r.

25 Ibidem, fol. $82 \mathrm{v}$.

26 Ibidem, fol. 59v. 
castellano junto al dominico fray Domingo de Rojas y Cristóbal de Ocampo ${ }^{27}$. La vecina ciudad de Toro, donde estaba el palacio de los marqueses de Alcañices, era el centro irradiador. D. ${ }^{a}$ Elvira de Rojas, marquesa viuda de Alcañices, daba cobertura en su corte nobiliaria a conversaciones, ideas, libros e individuos en continuo movimiento. Tenía a su servicio a Cristóbal de Padilla como camarero y tutor de sus hijos, a los que acompañó durante varios años en Salamanca. Su capellán era Sabino Astete, canónigo de Zamora, el ya citado amigo de Bartolomé de Carranza. Este, desde Flandes, en 1557, le enviaba a D. ${ }^{a}$ Elvira los cuadernos manuscritos de sus Comentarios al Catecismo Cristiano, que tanta polémica suscitaron después. De Toro fue corregidor, instalado en la ciudad, Don Carlos de Seso entre 1554 y 1557. El predicador real Agustín de Cazalla visitaba aquella casa coincidiendo con fray Domingo de Rojas, hermano de D. ${ }^{a}$ Elvira. Es bien posible que la marquesa se sirviera del buen hacer del bachiller toresano Herrezuelo, quemado en la hoguera en 1559. Al servicio de su hija, Ana Enríquez, se encontraba la beata Juana Velázquez, una de las mujeres devotas de Pedrosa, seguidoras de Pedro de Cazalla. Y Pedro de Sotelo, sobrino de Marina de Saavedra, era mayordomo de la casa. En aquel palacio se habían alojado las hermanas Vibero, Beatriz y Constanza, y era frecuentado por D. Juan de Ulloa Pereira, caballero de la Orden de San Juan de Jerusalén, desde los tiempos del corregimiento de Seso. Todos los mencionados aparecieron en los autos de fe de Valladolid de 1559, algunos murieron en la hoguera, otros fueron reconciliados. La marquesa viuda reunía en sus estancias sensibilidades espirituales de variados acentos afectivos que encontraban cálida acogida. En este círculo amplio pasaban de mano en mano los manuscritos de Carranza, las cartas de Juan de Ávila, la doctrina de fray Domingo de Rojas, las Ciento diez divinas consideraciones de Juan de Valdés, la Institutio Religionis Christianae de Calvino, y textos de Lutero y Brencio. Cómo fuesen leídos e interpretados estos textos, en qué clave, es difícil de precisar. En Pedrosa del Rey, varias personas celebraron la Santa Cena en sentido protestante en al menos dos ocasiones, con fray Domingo de Rojas al frente. En cualquier caso, y frente a la creencia generalizada de que Pedrosa del Rey y Valladolid fueron los ejes geográficos de referencia para los personas implicadas en estos círculos, creemos que hay que revalorizar el círculo de acogida de Toro liderado por la marquesa de Alcañices. Es significativo al respecto que cuando Cristóbal de Padilla se sintió en peligro no acudió a pedir consejo a Pedrosa del Rey ni a Pedro de Cazalla, sino al bachiller Herrezuelo de Toro.

En Zamora y Aldea del Palo, lugar cercano donde estaba el solar de los Sotelo, el círculo de relaciones de Padilla era muy amplio: miembros del cabildo catedralicio, de la Orden de San Juan de Jerusalén, de los dominicos... Pero fueron las mujeres las protagonistas y Marina de Saavedra fue el lazo con ese mundo. Los espacios de sociabilidad de esta mujer se vieron ahora coloreados por la nueva creencia. El proceso inquisitorial nos permite seguirla en su particular geografía de piedad, en aquellos lugares donde conversaba animadamente, donde seguía practicando obras de piedad aunque ahora con un carácter distinto.

27 Menéndez Pelayo, M.: Historia de los Heterodoxos Españoles, Madrid, Biblioteca de Autores Cristianos, 1986, vol. I, pp. 930-966. 
La casa de Marina de Saavedra era una casa abierta: de ella entraban y salían vecinos y familiares, como el sobrino Pedro de Sotelo. Todo encuentro era aprovechado para la conversación, especialmente cuando Padilla concurría. Y a la casa eran invitadas insistentemente amigas y conocidas a las que Marina ofrecía un espacio de diálogo seguro, "buscadme y me hallaréis" les decía ${ }^{28}$.

Fuera de la casa, Marina de Saavedra continuaba visitando hospitales, conventos e iglesias, aunque después de las conversaciones con Padilla no estaba tan motivada para la confesión auricular, ni la misa parecía tener el mismo carácter y los ayunos habían desaparecido de su agenda. Marina de Saavedra acudía a su parroquia, Santa María de la Horta, pero también iba más lejos, a la iglesia de Aldea del Palo (pequeña aldea de 180 vecinos hacia 1558); a Pontejos un pequeño pueblo muy próximo a Zamora donde vivía su hija Ana; al monasterio jerónimo de Montamarta. Dentro de la ciudad de Zamora frecuentaba sistemáticamente los beaterios de Santa Isabel y Santa Paula, además del monasterio de las monjas comendadoras de San Juan de Jerusalén, anexo a su propia parroquia de Santa María de Horta; y, en menor medida, los masculinos de San Jerónimo y Santo Domingo. En Santa Paula, solía quedarse a comer en animada conversación espiritual con algunas de las monjas-beatas y otros visitantes de ambos sexos. En algún caso, visitó a otras mujeres ofreciéndoles encuentros con Padilla en sus propias casas. Marina de Saavedra les dijo a una vecina y a una beata

que daba gracias a Dios por las mercedes que le había hecho, que tenía creído y entendía que por los méritos de su pasión de Dios le eran perdonados sus pecados... y esto respondió la dicha doña Ana que también había justificación y esta confesante le dijo y en justicia pues envió Dios a su hijo para que pagase por nosotros y por esta verdad moriré y le dijo a la dicha doña Ana que Padilla se lo había enseñado y que si quería que se lo enviaría a su casa ${ }^{29}$.

En todos esos espacios y tiempos Marina de Saavedra aparece como protagonista: reflexiona sobre las nuevas ideas, comparte sus dudas, expresa sus sentimientos... Creció su conciencia de la novedad de lo que compartía y de la necesidad del secreto. A una vecina Marina de Saavedra le dijo "yo se una luz muy buena que es muy provechosa e decirosla he pero no lo habeis de dezir a nadie" 30 . Y:

hablando con ciertas personas sobre cosas de la pasion de Dios les dixo esta confesante lo del purgatorio persuadiéndoles con una comparación de las que le dixo aquella persona que creyesen no aver purgatorio deziendoles que no era de pensar que la dicha persona quisiese yr al infierno e llevarlos consigo alla / E que una de aquellas personas con tristeza le pregunto que donde avian estado las animas de los difuntos / E que le respondió que en la gloria o infierno / E que la dicha persona se le encogio diziendo que no sabia nada / E que esta confesante le tornó a dezir creer lo que Dios manda que asi lo hago yo / E que encomendaba a las personas a quien dezia estas cosas el secreto dello. ${ }^{31}$

\footnotetext{
28 BNF, Mss. Esp. 456, fol. 18v.

29 Ibidem, fol. 40v.

30 Ibidem, fol. $17 \mathrm{v}$.

31 Ibidem, fol. 88r.
} 
Creció también su seguridad de formar parte de un grupo que participaba de un conocimiento no aceptado.

Y que otro dia siguiente estando la dicha enferma en artículo de morte avia ydo a visitarla [Marina de Saavedra] e la halló que ya no hablaba aunque entendía lo que le dezian, e delante de algunas personas que estaban presentes que ya entendían los dichos herrores dixo a la enferma, si se tenia por pecadora e que Dios avia venido al mundo por los pecadores y que la enferma le respondio que sí, e luego le tornó a dezir que creyese que por los meritos de la pasion de Cristo le eran perdonados sus pecados, e la enferma abaxo la cabeça haziendo señas que lo creya / E que así las personas que estaban presentes començaron a dezir bendito sea Dios que ha creido / E asi torno a dezir a la dicha persona enferma que no estribase en sus obras ${ }^{32}$.

Marina de Saavedra era analfabeta pero leía con los oídos. Los espacios de circulación de las nuevas ideas eran con frecuencia espacios comunitarios de lectura. Padilla solía traer un "librixo en las manos y dezía que eran epistolas de San Pablo, e le dezia por el dicho libro que era dotrina cristiana e cosa muy buena" ${ }^{33}$."E le leya algunas pocas cosas de un libro que dezia que era muy bueno, e después le declaraba lo que así le leya a proposito de lo que le dezia" ${ }^{34}$. Marina de Saavedra reunía en su casa a su hija y su cuñada, sus vecinas, sus criadas, formando una auténtica comunidad de lectura en la que Padilla les leía, sobre todo, una pequeña doctrina cristiana, atribuida a fray Domingo de Rojas, que gozó de mucho éxito especialmente entre las mujeres, y las cartas de Juan de Ávila que hablaban especialmente de la misericordia de Dios. ${ }^{35}$ Probablemente hubo otros espacios de lectura puesto que muchas cofradías tenían estipulados tiempos comunitarios para la lectura de textos edificantes y lo mismo sucedía en conventos y beaterios. Los lectores asimilaban los textos de manera personalísima y se convertían en propagadores de las nuevas ideas e informaciones ${ }^{36}$.

¿Qué creyó Marina de Saavedra? En su declaraciones y en los testimonios de su proceso encontramos los elementos básicos de las doctrinas protestantes, como la justificación por la fe juntamente con el rechazo de las obras como méritos de salvación:

que Jesucristo había padescido pasion por ella e la aceptase e tomase por suya porque Jesucristo era la cabeça e nosotros los miembros e que ansí su pasión era nuestra e que dixese al padre eterno, señor yo te ofrezco esta pasión que tu hijo precioso pasó por mi que El creó mía e yo te la ofrezco e por sola ella creo que soy perdonada de mis pecados e que si algo he rezado o hecho otras obras e la(s) fecho por tu amor e así te

32 Ibidem, fol. 88r.

33 Ibidem, fol. $45 \mathrm{v}$.

34 Ibidem, fol. 88v.

35 Sobre la importancia de estas comunidades de lectura en España, CASTillo Gómez, A.: "Leer en comunidad. Libro y espiritualidad en la España del Barroco", Vía Spiritus, 7 (2000), pp. 99-122. Y sobre el tema del beneficio de Cristo en Juan de Ávila, Giordano, M. L.: "La ciudad de nuestra conciencia". Los conversos y la construcción de la identidad judeo-cristiana (1449-1556)", Hispania Sacra LXII, 125 (enero-junio, 2010), pp. 43-91.

36 PeÑa, M.: "Libros permitidos, lecturas prohibidas (siglos XVI-XVII)", Cuadernos de Historia Moderna. Anejos, 1 (2002), pp. 85-101. 
las ofrezco e no por necesidad porque por sola tu pasión creo que soy perdonada, [..] no había necesidad de hazer otras obras ni rezar ni ayunar pues por sola la pasión de Jesucristo estavan perdonados [los pecados $].{ }^{37}$

la negación del purgatorio,

E que San Pablo dezia que las mugeres no predicasen a sus maridos / e por esto e por las razones e comparaciones que le dezia creyo esta confesante no aver purgatorio / aunque savia a la sazon y de presente que la Santa madre Yglesia tiene que ay purgatorio, e que por esto se dizen misas e se hazen sacrificios e otros sufragios, e que sin embargo de esto teniendo por bueno lo que aquella persona le dezia creyó no aver purgatorio $^{38}$.

que llevó a Marina a despreciar los ayunos y la compra de bulas y perdones:

que sacar para perdones es una suciedad e una burlería [...]; dixo que no era menester dar para perdones, que nuestro señor había hecho perdon general por su pasión y que no lo dijese a nadie ni hiciese caso dello aunque confesase, que era interés de clérigos [...]; que ya Dios no perdonaba por bullas sino por su propia sangre y luego dixo que Padilla lo decía ${ }^{39}$.

Ayunos, rezos y otras penitencias eran ya inútiles. Dijo Marina de Saavedra que "ya no se azotaba porque Nuestro Señor había pagado ya por todos" 40 . Las buenas obras ya no estaban guiadas por el miedo o simplemente la obediencia sino que eran la respuesta agradecida a la salvación previamente recibida de Dios en Cristo Jesús ${ }^{41}$. La confesión era un acto realizado ante Dios, mentalmente, donde se recibía el perdón; después se podía practicar la confesión auricular. Marina de Saavedra le dijo a su vecina "que quando se fuese a confesar se confesase antes a Dios mentalmente de todos sus pecados e tuviese arrepentimiento dellos que esta era la verdadera confesión e por aquella se perdonaban los pecados e después se confesase al sacerdote" y la vecina entendió "que la confision que se hacía a Dios mentalmente era la verdadera confesión e que la otra confesión [no hazía] el caso para la salvación ${ }^{42}$.

La eucaristía para Marina de Saavedra era ahora, fundamentalmente, un acto de limpieza espiritual, personal e íntima, que practicaba "por andar limpia en su servicio", al mismo tiempo que un acto de entrega, no de Dios al creyente, sino del creyente $\operatorname{Dios}^{43}$. Les enseñaba Padilla:

que aunque algunos días él no iba a la yglesia que nunca salía de [palabra incomprensible] que siempre él traía consigo porque la misa era la pasión e que él la aceptaba

\footnotetext{
37 BNF, Mss. Esp. 456, fol. 11v.

38 Ibidem, fol. ff. $11 \mathrm{v}-12 \mathrm{r}$.

39 Ibidem, fols. 18r, 26r. y 26v.

40 Ibidem, fol. 26r.

41 Ibidem, fol. 12r.

42 Ibidem, fol. 12r.

43 Ibidem, fol. 20r.
} 
siempre e la tenia por suya; mas dezía que dexasen lo pintado e fuesen a lo vivo que era lo bueno y lo fino y que quando oviesen de rescebir a Dios dixesen Señor recibeme tu a my, e daba esta razón que el mayor ha de recebir al menor ${ }^{44}$.

En las formas Dios estaba espiritualmente, no físicamente, porque a Dios había que adorarlo en espíritu. La misa se celebraba en el corazón como experiencia íntima. Afirmaciones peligrosas, sin duda, porque conducían a la devaluación del papel de los sacerdotes como mediadores con lo divino y a la negación de la doctrina de la transustanciación. El limbo dejó de existir para Marina: los niños gozaban de Dios según la fe de sus padres ${ }^{45}$. No hizo negación explícita de los santos pero sí recomendaba dirigirse directamente a Dios e invitaba a la adoración en espíritu, a mirar a lo alto, ante las imágenes:

Yten dixo que [...]que si queria alcanzar algo de Dios no curase de yr a los sanctos, sino a Dios porque los santos estaban embebidos, e que fuesen al rrío caudal que nunca se agota e no a la fuente / E quando le dezía las cosas sobredichas le dezía que aquello era Evangelio e porqué la avía de engañar ${ }^{46}$.

Marina empezó a cuestionar la autoridad de los obispos y del mismo Papa para perdonar los pecados. En Marina la alegría de la salvación recibida como don de Dios se plasmaba en una actitud cotidiana que daba nuevo significado a todo, desde las prácticas de piedad a la confesión auricular o la asistencia a misa, incluso ante las más importantes fiestas religiosas, ante la Cuaresma y la Semana Santa, que debían celebrarse no con tristeza sino con alegría por lo que Dios había hecho ${ }^{47}$.

El beneficio de Cristo, la justificación por la fe, las obras como respuesta a la obra salvífica de Dios y no como mérito necesario para la salvación, la alegría como se1lo, la misa como experiencia y celebración íntima de fe, la confesión como diálogo primero con Dios, la crítica anticlerical, la negación del purgatorio, la consideración sobre la confesión, el simbolismo o no de la Cena... eran temas muy vivos en el panorama teológico y espiritual español del siglo XVI. Individualizados, podemos rastrearlos entre corrientes franciscanas y dominicas, en el valdesianismo, y en el alumbradismo, que en los últimos años ha emergido como una auténtico eje vertebrador de la espiritualidad española del XVI ${ }^{48}$. En el proceso de Marina de Saavedra emergen las nuevas ideas no como un corpus dogmático elaborado pero sí como un conjunto de ideas o semillas fecundas en la vida de esta mujer, unas semillas fecundas

44 Ibidem, fol. 34r.

45 Ibidem, fol. 20v.

46 Ibidem, fol. $88 \mathrm{v}$.

47 La "alegría" como factor determinante de una espiritualidad distinta, como "buena nueva" y anuncio, ya la encontramos en los escritos del obispo Juan de Cazalla, y Stefania Pastore la ha rastreado entre los primeros alumbrados: PAstore, S.: "Mujeres, lecturas y alumbradismo radical: Petronila de Lucena y Juan del Castillo", Historia Social, 57 (2007), pp. 51-73.

48 Al respecto, además de PAstore, op. cit. y Boeglin, art. cit., (ambos en nota 6), ver García-ArenAL, M., y PeredA, F.: “A propósito de los alumbrados: confesionalidad y disidencia en el mundo ibérico", La Corónica, A Journal of Medieval Hispanic Languages, Literatures and Cultures 41-1 (2012), pp. 109-148; GIORDANO, M. L.: María de Cazalla (1487?-), Madrid, Ediciones del Orto, 1998. 
que implicaron una auténtica conversión piadosa. ¿Protestante de corazón, aunque no de razón?

\section{ANTE EL SANTO OFICIO: "SU DELITO FUE SIMPLICIDAD"}

Al inicio de la Pascua de 1558, el dominico fray Antonio de la Ascensión predicó un sermón impactante sobre la doctrina católica tal y como la entendía la Iglesia y anunció a los vecinos de Zamora que entre ellos había un hereje. Marina de Saavedra estaba en aquella iglesia junto a otras mujeres de su círculo. También Cristóbal de Padilla. Dirá más tarde la zamorana en su proceso que en ese momento supo, supieron, ella y sus hijas, vecinas y criadas, que habían sido engañadas. Se desató el miedo. Los que habían escuchado con simpatía hasta aquel momento las pláticas de Padilla corrieron ahora a descargar sus conciencias ante el obispo de Zamora. La ciudad se vio sacudida por la sospecha y el pánico a niveles insoportables Un indicador de este terror es el caso que le hicieron el tundidor de Valladolid Pedro Aguilar, que se disfrazó de alguacil del Santo Oficio y se fue a Zamora donde amenazó con detener a varias personas e incluso hizo exhumar los restos de un ilustre personaje ${ }^{49}$.

El proceso inquisitorial contra Marina de Saavedra se inició oficialmente a finales de junio de 1558. Sus declaraciones a lo largo del proceso estuvieron guiadas por una estrategia de exculpación o, por lo menos, de limitación de daños colaterales. Protegía a su marido y sus dos hijas. Sus seis hijos varones no son mencionados en ningún momento. La trayectoria de sus declaraciones fue: de la negación a la totalidad, según el discurso retórico de los abogados defensores asignados por el Santo Oficio, a la asunción de contradicciones y, finalmente, la aceptación de detalles y prácticas que los inquisidores ya conocían. Reconoció haber creído durante un breve tiempo en esas ideas nuevas pero desconocía su peligrosidad y, desde luego, nunca fue dogmatizadora ni tuvo voluntad de engañar a otros. Si creyó fue por su condición femenina, débil y confiada, que la habría llevado a dar oídos a un hombre de crédito como Cristóbal de Padilla.

El 7 de marzo de 1559 los inquisidores dieron por probados los cargos del fiscal y condenaron a Marina de Saavedra a reconciliación con cárcel perpetua, hábito irremisible y confiscación de bienes. Se le leyó la sentencia en el auto de fe de 21 de mayo de 1559. En ese auto de fe y en el posterior, del 8 de octubre del mismo año, aparecieron todos los zamoranos directamente relacionados con Marina de Saavedra: Pedro de Sotelo, Cristóbal de Padilla y Cristóbal Docampo fueron condenados a la hoguera, su vecina Leonor de Toro recibió la misma sentencia que ella. Los que no salieron al auto recibieron penas menores.

Inmediatamente después de la finalización del auto de fe y a petición de su marido, Marina de Saavedra fue llevada a Zamora para ser custodiada en casa de un pariente. Tres días después su marido solicitó que le fuera entregada su esposa para custodiarla en su casa de Aldea del Palo porque a sus habituales enfermedades añadía ahora que

49 Bennassar, op. cit. (nota 19), p. 390. Aguilar apareció en el auto de fe de 8 de octubre de 1559. 
estaba "fuera de juicio". ${ }^{50}$ No sabemos cuándo pero suponemos que tras la mejoría de su enfermedad Marina de Saavedra volvió a las cárceles inquisitoriales de Valladolid, en celda compartida con Leonor de Cisneros, que moriría en la hoguera por reincidente en 1567, y Ana Enríquez, hija de la marquesa de Alcañices. Una compañía poco propicia para desandar el camino de la heterodoxia. Pero las enfermedades seguían acosándola y a principios del otoño de 1563 suplicaba patéticamente a los inquisidores que le permitiesen volver a su casa a pasar el invierno: "porque yo me tollezco de la enfermedad de la perlesía y desta manera podría remediar mi necesidad para adelante y otra ninguna yo la siento para poder vivir" ${ }^{51}$. Volver a casa. Ese fue el último deseo de Marina de Saavedra documentado en su proceso.

Después del auto de fe, los Cisneros de Sotelo iniciaron una impresionante estrategia para recuperar el honor y los bienes perdidos. Desde el verano de 1559, su marido planteó batalla legal contra la cámara real y fisco del Santo Oficio para recuperar su patrimonio tras la confiscación. Se abrió un proceso fiscal en el que el argumento principal fue que la inmensa mayoría de los bienes confiscados eran propiedad del marido desde antes del matrimonio con Marina de Saavedra cuya dote ni siquiera había llegado a ser pagada en su totalidad ${ }^{52}$.

Por otro lado, en 1560 los hijos mayores solicitaron de los inquisidores un documento notarial que acreditase que, a pesar de la herejía cometida por su madre, ellos eran hábiles para tomar el hábito de la orden de San Juan de Jerusalén y entrar en la prestigiosa Cofradía de San Nicolás de los Caballeros de Zamora. Su madre, ya viuda, vivía ahora muy cristianamente y si erró "su delicto fue simplicidad y sobrado crédito que dio a algunas personas de quien ella confiava" 53 . Por otro lado, precisaban, todos sus hijos nacieron mucho antes de que ella incurriese en herejía. Los inquisidores emitieron un documento un tanto ambiguo de habilitación ${ }^{54}$. Siete años más tarde, en 1567, los hijos varones más pequeños volvieron a solicitar un documento notarial más explícito con el mismo fin. En esta ocasión, la familia jugó fuerte y contrató los servicios de uno de los abogados más prestigiosos del momento, el Dr. Martín de Azpilcueta, abogado defensor del arzobispo Carranza, en las cárceles inquisitoriales en aquellas fechas ${ }^{55}$.

Finalmente, en 1570, Francisco de Sotelo, yerno de Marina de Saavedra y patrón del Hospital de Sotelo, el más importante de Zamora, vinculado a la familia, escribía desde Roma para informar a los patronos que había logrado las reliquias de San Cenón, obispo de Verona que había destacado por su lucha contra le herejía arriana, para el Hospital. El capital económico, social y simbólico del linaje de los Sotelo parecía quedar a salvo ${ }^{56}$. Se había conjurado el peligro de la infamia.

50 BNF, Mss. Esp. 456, fol. 93r.

51 Ibidem, fol. 94r.

52 AHN, Inquisición, leg. 4599, exp. 6 y 7.

53 BNF, Mss. Esp. 456, fol. 95r.

54 Ibidem, fol. $93 \mathrm{v}$.

55 Real Biblioteca de El Escorial, Sig. 33-I-9, n. 17. Iuris responsum D. Martini de Azpilcueta, Doctoris Navarri, ff. 1-6v.

56 Archivo de la Diputación de Zamora, Leg. 87, exp. 56. 
¿Qué pasó con Marina de Saavedra? ¿Cuál fue su fin? He buceado en los archivos zamoranos hasta ahora sin éxito. La declaración de los hijos en 1566 subrayaba que su madre viuda vivía ya muy conformada por las prácticas de la ortodoxia. Siempre nos quedará la incógnita de saber si esa vuelta a la ortodoxia fue algo más que una conformación exterior, una re-conversión a la piedad católica, o bien si durante todo este proceso, marcado por una interiorización creciente de la fe y la experiencia espiritual, Marina de Saavedra descubrió que podía mantener las formas externas al mismo tiempo que una morada interior y profunda, más libre, donde mantener la alegría y el diálogo personal con su Dios.

\section{CONCLUSIÓN}

¿Marina de Saavedra tenía raíces conversas? No hemos encontrado ningún indicio hasta el momento de esto. ¿Fue nuestra protagonista protestante?, ¿alumbrada?, ¿una mujer devota ansiosa de reforma espiritual? Los testimonios del proceso nos llevan a considerar que en los primeros meses de 1558 Marina de Saavedra se deslizaba en dirección hacia un protestantismo esencial. Esta última afirmación, desde luego, hay que entenderla en el contexto de la espiritualidad de la España de la primera mitad del siglo XVI, época rica en fermentos religiosos complejos y diferentes que condicionaron la recepción de las doctrinas reformadas, adaptándolas y/o diluyéndolas. En cualquier caso, la acción inquisitorial logró reconciliar a Marina de Saavedra y reinsertarla en el mundo de la ortodoxia, según el testimonio interesado de sus hijos.

Más allá de la identidad religiosa de Marina de Saavedra, que huye de una etiqueta rígida y estática, el estudio de su proceso inquisitorial, no estudiado hasta el momento, complementado con otras fuentes, nos ha permitido reconstruir el contexto social y espiritual de una mujer laica e iletrada, arraigada en las particulares estructuras sociales y familiares de la ciudad de Zamora. Marina de Saavedra se nos muestra como un agente divulgador activo de las ideas protestantes en sus círculos de sociabilidad femenina, a través de conversaciones y lecturas en comunidad, en espacios privados y semi-privados, como los beaterios zamoranos. El caso de Marina de Saavedra nos ha permitido trazar los caminos de la circulación de las nuevas ideas y la facilidad de su divulgación discreta en esos círculos de religiosidad laica poco controlados por la Iglesia anterior a Trento. El fundamental y activo papel de las mujeres en este proceso queda bien ejemplificado en Marina de Saavedra. 